\title{
BMJ Open Trends in educational and wealth inequalities in adult tobacco use in Nepal 2001-2016: secondary data analyses of four Demographic and Health Surveys
}

Chandrashekhar T Sreeramareddy, ${ }^{\circledR 1}$ Sam Harper ${ }^{2}$

To cite: Sreeramareddy CT, Harper S. Trends in educational and wealth inequalities in adult tobacco use in Nepal 2001-2016: secondary data analyses of four Demographic and Health Surveys. BMJ Open 2019;9:e029712. doi:10.1136/ bmjopen-2019-029712

- Prepublication history and additional material for this paper are available online. To view these files, please visit the journal online (http://dx.doi. org/10.1136/bmjopen-2019029712).

Received 08 February 2019 Revised 17 July 2019 Accepted 18 July 2019

Check for updates

(c) Author(s) (or their employer(s)) 2019. Re-use permitted under CC BY-NC. No commercial re-use. See rights and permissions. Published by BMJ.

${ }^{1}$ Department of Community Medicine, International Medical University School of Medicine, Kuala Lumpur, Malaysia ${ }^{2}$ Department of Epidemiology and Biostatistics and Occupational Health, McGill University, Montreal, Quebec, Canada

Correspondence to Dr Chandrashekhar T Sreeramareddy; chandrashekharats@yahoo.com

\section{ABSTRACT}

Objective To measure trends in socioeconomic inequalities tobacco use in Nepal.

Setting Adults interviewed during house-to-house surveys.

Participants Women (15-45 years) and men (15-49 years) surveyed in four Nepal Demographic and Health Surveys done in 2001, 2006, 2011 and 2016.

Outcome measure Current tobacco use (in any form). Results The prevalence of tobacco use for men declined from $66 \%$ in 2001 to $55 \%$ in 2016, and declined from $29 \%$ to $8.4 \%$ among women. Across both education and wealth quintiles for both men and women, the prevalence of tobacco use generally declines with increasing education or wealth. We found persistently larger absolute inequalities by education than by wealth among men. Among women we also found larger educational than wealth-related gradients, but both declined over time. For men, the Slope Index of Inequality (SII) for education was larger than for wealth (44\% vs $26 \%$ in 2001) and changed very little over time. For women, the SIl for both education and wealth were similar in magnitude to men, but decreased substantially between 2001 and 2016 (from $44 \%$ to $16 \%$ for education; from $37 \%$ to $16 \%$ for wealth). Women had a larger relative index of inequality than men for both education (6.5 vs 2.0 in 2001) and wealth (4.8 vs 1.5 in 2001), and relative inequality increased between 2001 and 2016 for women (from 6.5 to 16.0 for education; from 4.8 to 12.0 for wealth).

Conclusion Increasing relative inequalities indicates suboptimal reduction in tobacco use among the vulnerable groups suggesting that they should be targeted to improve tobacco control.

\section{BACKGROUND}

Tobacco smoking remains a leading risk factor for premature mortality and morbidity worldwide, causing nearly five million deaths annually since $1990 .{ }^{1}$ Smoking is among the top five risk factors contributing to disability adjusted life years (DALYs) lost for 109 countries in 2016. ${ }^{2}$ The 2016 global age-standardised prevalence of tobacco use was $25 \%$
Strengths and limitations of this study

- Four nationally representative sample from Demographic and Health Surveys done sequentially at 5-year intervals enabled us to assess time trends in tobacco use inequalities.

- We estimated summary measures of both absolute and relative inequalities of tobacco use by wealth and education, disaggregated by sex.

- Crude as well as age-standardised rates of tobacco use and measures of inequalities were estimated as a sensitivity analyses.

- Tobacco use prevalence estimates based on self-reports are likely to be underestimated due to social desirability bias.

- We were unable to link changes in inequalities in tobacco use to the implementation of tobacco control policies during 2000-2016, due to descriptive nature of our analyses.

among men and 5\% among women, and has decreased by nearly a third since $1990 .^{3}$ Smokeless tobacco also contributes to the global burden of disease accounting for some 1.7 million DALYs lost and 62283 deaths annually due to cancers of mouth, pharynx and oesophagus. The majority of this burden occurs in Southeast Asian countries. ${ }^{4} 5$ Smoking, including smokeless tobacco, not only negatively impacts individual and population health ${ }^{6}$ but also causes economic loss through increased healthcare costs and the loss of productive years from disease and premature death. $^{7}$

Socioeconomic position is known to be associated with health status, ${ }^{8}$ and tobacco use has been demonstrated to show strong social patterning. ${ }^{9}$ Populations occupying lower socioeconomic position generally have higher prevalence of tobacco use ${ }^{10}$ which contributes to health and mortality inequalities. ${ }^{11}$ Socioeconomic inequalities in smoking 
Table 1 Age-standardised prevalence differences and Slope Index of Inequality (SII) for tobacco use among men and women by education and wealth, Nepal Demographic and Health Surveys 2001, 2006, 2011 and 2016

\begin{tabular}{|c|c|c|c|c|c|}
\hline & 2001 & 2006 & 2011 & 2016 & P value ${ }^{\star}$ \\
\hline \multicolumn{6}{|l|}{ Men } \\
\hline \multicolumn{6}{|c|}{ Rate difference $(95 \% \mathrm{Cl})$} \\
\hline Primary & 36.3 (26.3 to 46.4$)$ & 36.5 (30.6 to 42.4$)$ & 37.0 (30.5 to 43.5$)$ & 36.5 (29.4 to 43.5$)$ & 0.999 \\
\hline Secondary & $11.2(0.3$ to 22.1$)$ & $19.2(12.4$ to 26.0$)$ & 17.2 (11.8 to 22.5$)$ & 22.3 (17.8 to 26.8$)$ & 0.215 \\
\hline \multicolumn{6}{|c|}{ Rate difference $(95 \% \mathrm{Cl})$} \\
\hline Poorest & 19.0 (10.5 to 27.6$)$ & $22.5(15.0$ to 30.1$)$ & 26.3 (19.0 to 33.5 ) & 21.5 (15.2 to 27.7$)$ & 0.618 \\
\hline Poorer & 28.2 (20.8 to 35.6$)$ & 19.2 (12.0 to 26.4$)$ & 20.9 (14.1 to 27.8$)$ & 21.0 (13.5 to 28.4$)$ & 0.302 \\
\hline Middle & 20.8 (13.0 to 28.7$)$ & $12.0(4.6$ to 19.4$)$ & 22.7 (15.3 to 30.0$)$ & 22.6 (16.3 to 28.8$)$ & 0.130 \\
\hline \multicolumn{6}{|l|}{ Women } \\
\hline \multicolumn{6}{|c|}{ Rate difference $(95 \% \mathrm{Cl})$} \\
\hline No education & 29.2 (25.5 to 33.0$)$ & 24.2 (21.7 to 26.7$)$ & 16.7 (14.4 to 19.0$)$ & 10.4 (8.9 to 11.8$)$ & $<0.001$ \\
\hline Primary & 16.7 (12.6 to 20.8$)$ & 15.1 (12.0 to 18.3$)$ & 12.5 (9.8 to 15.2$)$ & 7.2 (5.6 to 8.7$)$ & $<0.001$ \\
\hline Secondary & $3.4(0.2$ to 6.6$)$ & 2.2 (0.8 to 3.7 ) & 3.0 (2.1 to 3.9$)$ & 1.7 (0.9 to 2.5$)$ & 0.192 \\
\hline \multicolumn{6}{|c|}{ Higher education (ref.) } \\
\hline SII (95\% Cl) & 44.4 (38.5 to 50.3$)$ & 40.4 (35.9 to 44.9$)$ & 26.2 (21.8 to 30.5$)$ & 16.0 (13.5 to 18.6$)$ & $<0.001$ \\
\hline \multicolumn{6}{|c|}{ Rate difference $(95 \% \mathrm{Cl})$} \\
\hline Poorest & 28.9 (24.4 to 33.4$)$ & 29.5 (25.3 to 33.7$)$ & 23.5 (19.1 to 28.0 ) & 14.2 (12.2 to 16.3$)$ & $<0.001$ \\
\hline
\end{tabular}

${ }^{*} \mathrm{P}$ value for test of heterogeneity in rate difference or SIl across years.

by education and wealth have been documented in a number of high-income countries. ${ }^{12-15}$ Our previous work on tobacco use in south and Southeast Asian ${ }^{16}$ and sub-Saharan African countries ${ }^{17}$ showed that wide differentials in tobacco use exist by gender, as well as considerable variation between countries in the magnitude of differentials by wealth and education. ${ }^{18}$ A number of studies using cross-sectional surveys from high-income countries have also reported on educational inequalities in tobacco smoking, ${ }^{12}$ though fewer have assessed wealth-related inequalities. ${ }^{141519}$ Although measuring inequalities presents a number of methodological challenges, measuring their magnitude provides useful information for policy making, ${ }^{20}$ as well as providing the potential to assess the impact tobacco control policy interventions consistently and equitably across the population subgroups. ${ }^{21} 22$

Monitoring health inequalities at the national level provides benchmarks for policies, programmes and practices that tackle health inequalities, as well as assessing progress (or a lack thereof) towards equity goals and targets. ${ }^{23}$ However, few studies have evaluated trends in socioeconomic inequalities in tobacco in low/middle-income countries (LMICs), ${ }^{19} 2425$ and no studies have done so in Nepal. We aimed to study trends in socioeconomic inequalities in Nepal using Demographic and Health Surveys (DHS) conducted in 2001, 2006, 2011 and 2016.

\section{METHODS}

\section{Ethics statement}

Written permission was obtained from Government of Nepal for all surveys. Informed consent was sought from each survey participants as per the international guidelines.

\section{Data source}

The Nepal DHS was implemented by the measuredhs programme which collects data on fertility, family 
planning, health and nutrition, health services utilisation, health knowledge and behaviours from adult men and women from serial surveys in over 80 LMICs. Trained interviewers collected the data in separate standardised questionnaires from eligible adult women (15-49 years) and men (15-49 years) living in the sampled households through face-to-face interviews during in-home surveys. Men were selected for the interview in a subsample of households; hence, fewer men than women were sampled each survey wave. Nepal's DHS uses a two-stage stratified cluster sampling design, with urban and rural clusters selected by probability proportional to size, followed by a random selection of households within the selected clusters. Details of the DHS are described elsewhere. ${ }^{26}$

\section{Main outcome variable}

Tobacco use in any form was computed based on the responses given to the questions about the use of tobacco products. We defined tobacco use similarly as in previous publications based on DHS data. ${ }^{18}$ The following four questions (response options) were asked separately for men and women:

1. Do you currently smoke cigarettes? (response as 'yes' or 'no').

2. In the last 24 hours, how many cigarettes did you smoke? (response as number).

3. Do you currently smoke or use any other type of tobacco? (response as yes or no).

4. What (other) type of tobacco do you currently smoke or use? (options given were pipe, chewing tobacco, snuff and others).

Our main outcome of 'current tobacco user' was a binary variable equal to one if the respondents replied yes to the questions on current cigarette smoking, current smoking of pipe, cigars and so on or use any other type of tobacco products such as chewing tobacco, snuff and so on. Multiple tobacco product users were also included in the definition of current tobacco use.

Crude prevalence differences for men
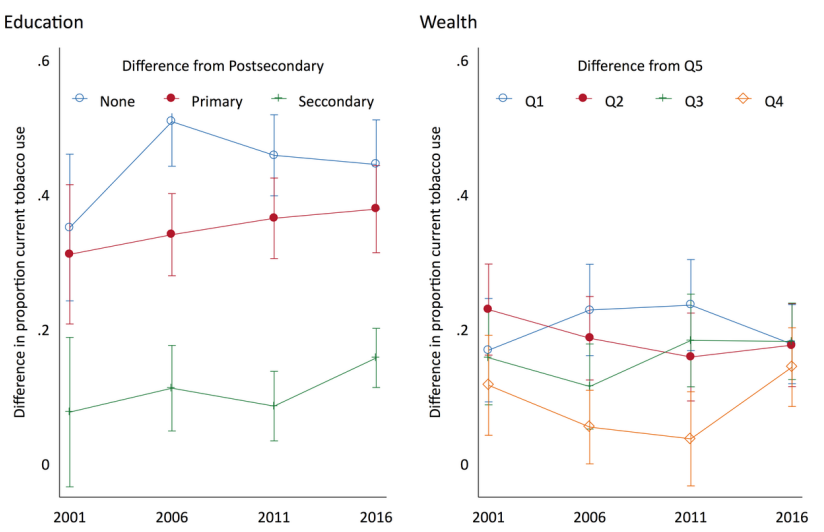

Figure 1 Crude prevalence differences for tobacco use among men by education and wealth, Nepal Demographic and Health Surveys 2001, 2006, 2011 and 2016.
We used two primary stratification variables for assessing inequalities: educational attainment and a wealth index. Educational attainment was measured as the highest grade completed by the respondent (none, at least primary, at least secondary, post-secondary). The wealth index was constructed using an asset-based index,${ }^{27}$ which was categorised into survey-specific quintiles. The items included in the estimation of wealth index were (1) type of flooring, (2) refrigerator, (3) water supply, (4) type of vehicle, (5) sanitation facilities, (6) persons per sleeping room, (7) electricity, (8) ownership of agricultural land, (9) radio and (10) television.

\section{Patient and public involvement}

This study was a secondary data analyses of data available in the public domain. Patients and the public were not involved.

\section{Statistical analysis}

We calculated crude and age-standardised prevalence rates of current tobacco use in each survey year. We accounted for the DHS complex sampling design when estimating SEs through the use of Stata's 'svy' commands (Stata V.14) for survey data. We pooled all survey years and used logistic regression to estimate the log odds of reporting current tobacco use as a function of survey year, social group (education group or wealth quintile) and product terms to allow the social group-specific coefficient (education or wealth quintile) to vary by survey year. We used these models to generate marginal predicted estimates of the prevalence of smoking, and constructed prevalence differences and ratios comparing the estimated prevalence of tobacco use in each group to the group with the highest education or in the highest wealth quintile. As an additional analysis (see online supplementary file 1), we also included a series of indicators for 5-year age groups and constructed marginal predictions, differences and ratios standardised to the WHO's 2000 age standard. ${ }^{28}$

To facilitate analysis of changes over time, we also calculated two summary measures of inequality: the Slope Index of Inequality (SII) and Relative Index of Inequality (RII). ${ }^{29}$ These measures are constructed by regressing current tobacco use on each social group's relative rank (ie, ridit score from 0 to 1 ) in the cumulative distribution of education (or wealth) in each survey year. As for the analysis of prevalence by social group, we pooled all survey years and regressed current tobacco use on the cumulative rank variable, indicators for survey year and product terms between rank and year. Marginal predictions from these models were used to estimate the predicted probability of tobacco use at the bottom (rank=0) and the top (rank=1) of the education (or wealth) distribution, assuming a linear relationship between rank and tobacco use on the log odds scale. The SII and RII provide, respectively, measures of absolute and relative inequality. The SII is the absolute difference is predicted tobacco use at the bottom versus the top of the socioeconomic distribution, and the RII is the ratio of these two predictions. 
Table 2 Relative Index of Inequality (RII) of tobacco use among men and women by education and wealth in Nepal Demographic and Health Surveys 2001, 2006, 2011 and 2016

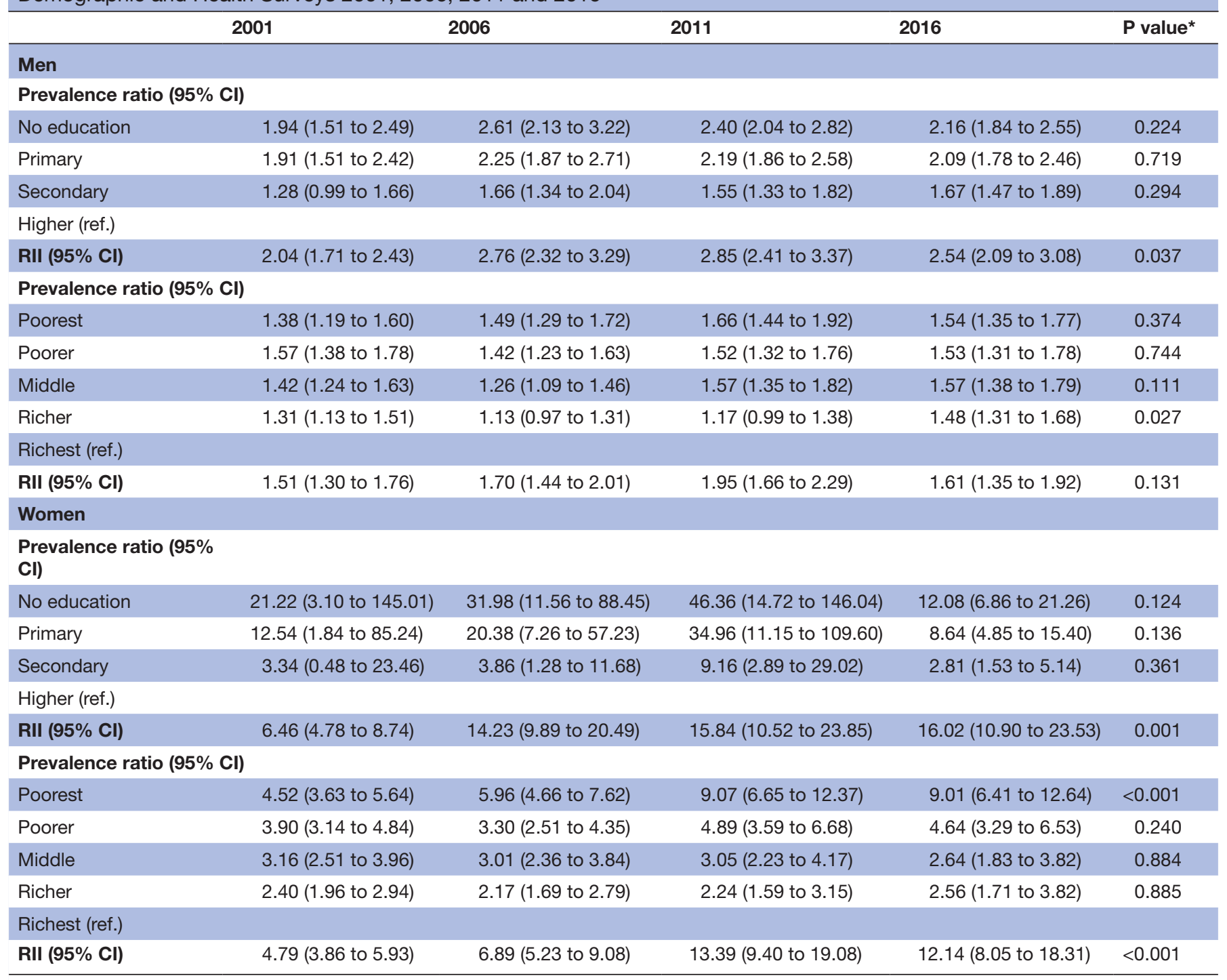

${ }^{*} \mathrm{P}$ value for test of heterogeneity in log prevalence ratio or Rll across years.

Crude prevalence differences for women
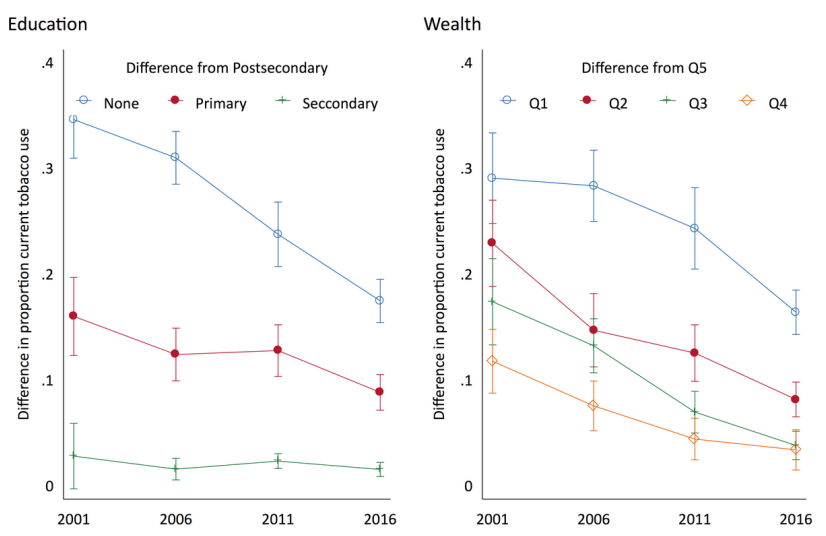

Figure 2 Crude prevalence differences for tobacco use among women by education and wealth, Nepal Demographic and Health Surveys 2001, 2006, 2011 and 2016.
SEs were calculated using the delta method. All analyses were conducted separately by gender. We tested for heterogeneity in the SII and (log) RII across successive survey waves using Wald tests of composite linear hypotheses. The code to reproduce these estimates is available in a public repository (https://osf.io/c9e $5 \mathrm{n} /$ ), and the raw DHS files may be obtained via request from the DHS website (https://dhsprogram.com/).

\section{RESULTS}

Table 1 shows the age-standardised socioeconomic differences in current tobacco use for men and women in each survey year. Not surprisingly, the prevalence was considerably higher for men than women, but the prevalence for both men and women has declined over time. The prevalence for men declined from $66 \%$ in 2001 to $55 \%$ in 2016, and declined from $29 \%$ to $8.4 \%$ for women 
(online supplementary table). Across both education and income, and for both men and women, the prevalence of tobacco use generally declines with increasing education or wealth.

Figures 1 and 2 show the estimated crude prevalence differences for men and women, respectively, as well as how they have changed over successive surveys. Figure 1 shows somewhat larger educational differences than wealth differences in the probability of tobacco use among men, but for both dimensions the differences are more or less stable over time. On the other hand, figure 2 shows, for women, considerably larger educational and wealth-related gradients, as well as larger declines over time in inequalities in both dimensions. Age-standardised trends in prevalence differences were nearly identical (see appendix for age-standardised online supplementary tables and online supplementary figures 1 and 2). Table 1 provides estimates of the SII, by gender, for education and wealth inequalities. The SII for men in 2001 was 43.9, indicating that, assuming a linear relation between education and the log-odds of smoking, the prevalence of smoking increases by 44 percentage points as one moves from the top (highest) to the bottom (lowest) of the education distribution. The SII for wealth among men was smaller, around 26 percentage points, but, as measured by the SII, there was little change over time in the magnitude of absolute inequalities for men. Table 1 also shows SIIs for education and wealth for women, which were similar in magnitude to those for men, but decreased substantially. The SII for education among women decreased from 44 to 16 percentage points between 2001 and 2016, and the SII for wealth-related inequalities decreased from 37 to 16 percentage points. Table 2 shows measures of relative inequality: prevalence ratios and the RII. Relative inequalities were larger for women than men, but also more imprecise due to the lower prevalence, especially among the most advantaged groups of women. In contrast to the estimates for absolute inequality, relative inequalities increased for both men and women (much more so for the latter) from 2001 to 2016.

\section{DISCUSSION}

We found that the overall prevalence of tobacco use decreased over time among both men and women in Nepal. However, declines were much steeper for women than men and the prevalence of tobacco use continues to be substantially higher among men than women. Time trends in inequalities shed light on differing pattern of inequalities by both education and wealth. Absolute inequalities among men by both education and wealth did not change over time, suggesting similar absolute declines among sub groups, whereas absolute inequalities declined substantially among women. Relative inequalities increased among both men and women between 2001 and 2016.

The main strength of our report was the availability of large nationally representative samples of men and women from four standard DHS implemented nearly at 5-year intervals. DHS has collected information on tobacco use based on same questions in all four surveys allowing us to compute the main outcome variables as current tobacco user. This enabled us to compare four surveys to assess the time trends in tobacco use inequalities. To the best of our knowledge, this is the first report on time trends of tobacco inequalities in terms of both education and wealth for Nepal. Another strength was estimation of weighted, age-standardised prevalence rates, and the inclusion of both absolute and relative measures of inequalities.

Nevertheless, our findings should be interpreted in the light of some limitations. First, it is well known that validity of self-reported tobacco use may be questionable, since tobacco use is likely to be under-reported due to social desirability bias, ${ }^{30}$ particularly among women. ${ }^{31}$ Though self-reported estimates of tobacco use in the general population are valid, ${ }^{32}$ we cannot rule out whether there were any systematic differences in self-reported tobacco use by socioeconomic position, or whether any differences may have changed across survey waves. Second, DHS are primarily designed to obtain indicators of reproductive and child health. Hence, the sample size was designed primarily for the women's survey and men were only interviewed in a subsample of selected households. ${ }^{26}$ This may have reduced the precision of prevalence estimates and measures of inequality for men. Third, our analysis is descriptive and does not provide information on the causes for either persisting or widening inequalities. Although Nepal has implemented some tobacco control policies over the period 2000-2016, our study does not provide any evidence for their impact on overall prevalence or inequalities.

The prior literature on inequality trends in LMICs is limited to only one study from India which assessed inequalities in different forms of tobacco use and reported the differences in prevalence rates by socioeconomic groups. ${ }^{33}$ Our results are difficult to compare with the study from India because summary measures of socioeconomic inequality were not estimated. A study from Germany assessed the trends in educational inequalities for current smoking ${ }^{25}$ but our study used any tobacco use as the main outcome measure because smokeless tobacco use is widely prevalent in Nepal. Nevertheless, socioeconomic inequalities in smoking have persisted ${ }^{24} 3435$ over last few decades or even widening in developed countries. ${ }^{36-39}$ Studies from developed countries which examined trends in both absolute and relative inequalities have consistently reported that relative inequalities have increased over a time period ${ }^{35} 3638$ similar to the trend we report from Nepal.

Why might relative inequalities have increased in Nepal despite decreasing prevalence rates, particularly among women? One possible explanation is the 'reverse equity hypothesis', which proposes that changes in inequalities evolve over stages of the tobacco epidemic. ${ }^{40}$ Tobacco control interventions in Nepal began in Nepal with 
signing the Framework Convention Tobacco Control on 3 December 2003 and its ratification on 7 November 2006. Following this, Nepal passed the primary law governing tobacco control, the Tobacco Product (Control and Regulatory) Act, of 2011. ${ }^{41}$ Tobacco control measures such as taxation, smoke-free policies and anti-media campaigns are still new interventions that are likely to be adopted at first by wealthier and better educated individuals, which may have led to widening of inequalities. Large summary measures of relative inequality for women are likely a consequence of very low prevalence of tobacco use among the most advantaged women. For example, in the 2016 NDHS prevalence of tobacco use was $<1.0 \%$ among women who had attained higher education, so even small decreases in this population can generate large increases in relative inequality. This illustrates another reason why it is important to report both absolute and relative measures of inequality when evaluating temporal trends. Somewhat more optimistically, the reverse equity hypothesis also proposes that over a longer time horizon and after sustained implementation of tobacco control interventions among disadvantaged populations, even relative inequalities may narrow, though in some rich countries in advanced stages of the tobacco epidemic (eg, Canada), this has not yet been observed. ${ }^{42}$

Among developed countries it is unclear whether population-level tobacco control interventions will benefit socially disadvantaged populations. ${ }^{22}$ Our findings suggest that even in LMIC disadvantaged socioeconomic groups need to be considered for more targeted implementation of specific tobacco control measures to reduce inequalities. Specific measures such as improving awareness about smoking-related health effects through mass media, graphic and pictorial warnings on tobacco products, sales regulation and provision of smoking cessation services should be considered. ${ }^{41}$ Specific attention should also be given to the distal drivers of tobacco consumption such as socioeconomic deprivation. ${ }^{43}$ Smokeless tobacco use should also be given special attention in Nepal, as control of smokeless tobacco is often under-emphasised in tobacco control policy. Continued monitoring of socioeconomic inequalities is needed in Nepal to observe if the widening relative inequalities will narrow in forthcoming years. Data from DHS carried out at roughly 5 years intervals are well suited for monitoring trends in socioeconomic inequalities in smoking and/tobacco use in other developing countries as well.

\section{CONCLUSION}

We found persistent absolute inequalities in tobacco use among men but declining absolute inequalities among women. Increasing relative inequalities, particularly among women, suggest that tobacco use has become highly concentrated among disadvantaged women. Tobacco control strategies should target these vulnerable groups for optimal tobacco control that will both reduce overall prevalence and reduce inequalities.
Acknowledgements Authors thank the Demographic Health Surveys for providing sharing the data with to prepare this report.

Contributors CTS designed the study, did preliminary data analyses and wrote the first draft of the manuscript. SH did a detailed analysed of the data. Both the authors contributed to interpreting the findings and revising the manuscript through various drafts.

Funding The authors have not declared a specific grant for this research from any funding agency in the public, commercial or not-for-profit sectors.

\section{Competing interests None declared.}

Patient consent for publication Not required.

Ethics approval All the Demographic and Health Survey protocols are approved by the Institutional Review Board (IRB) of ORC Macro and NewEra, the implementing agency in Nepal. Ministry of Health and Population, Government of Nepal had approved all surveys. Institutional review board approval was not required since this study was based on secondary analyses of publicly available, deidentified data.

Provenance and peer review Not commissioned; externally peer reviewed.

Data availability statement Extra data can be accessed via the Dryad data repository at http://datadryad.org/ with the doi: 10.5061/dryad.qn275kk

Open access This is an open access article distributed in accordance with the Creative Commons Attribution Non Commercial (CC BY-NC 4.0) license, which permits others to distribute, remix, adapt, build upon this work non-commercially, and license their derivative works on different terms, provided the original work is properly cited, appropriate credit is given, any changes made indicated, and the use is non-commercial. See: http://creativecommons.org/licenses/by-nc/4.0/.

\section{REFERENCES}

1. Forouzanfar MH, Afshin A, Alexander LT, et al. Global, regional, and national comparative risk assessment of 79 behavioural, environmental and occupational, and metabolic risks or clusters of risks, 1990-2015: a systematic analysis for the global burden of disease study 2015. The Lancet 2016;388:1659-724.

2. Gakidou E, Afshin A, Abajobir AA, et al. Global, regional, and national comparative risk assessment of 84 behavioural, environmental and occupational, and metabolic risks or clusters of risks, 1990-2016: a systematic analysis for the global burden of disease study 2016. The Lancet 2017;390:1345-422.

3. Reitsma MB, Fullman N, Ng M, et al. Smoking prevalence and attributable disease burden in 195 countries and territories, 19902015: a systematic analysis from the global burden of disease study 2015. The Lancet 2017;389:1885-906.

4. Siddiqi K, Shah S, Abbas SM, et al. Global burden of disease due to smokeless tobacco consumption in adults: analysis of data from 113 countries. BMC Med 2015;13:194.

5. Sinha DN, Suliankatchi RA, Gupta PC, et al. Global burden of allcause and cause-specific mortality due to smokeless tobacco use: systematic review and meta-analysis. Tob Control 2018;27:35-42.

6. Jha P, Peto R. Global effects of smoking, of quitting, and of taxing tobacco. N Engl J Med 2014;370:60-8.

7. Victor UE, Abraham KB. The economic impact of smoking and of reducing smoking prevalence: review of evidence. Tob Use Insights 2015;8:1-35.

8. Marmot M. The status syndrome: how your social standing affects your health and life expectancy. London: Bloomsbury, 2004: 1. 150-4.

9. Hiscock R, Bauld L, Amos A, et al. Socioeconomic status and smoking: a review. Ann N Y Acad Sci 2012;1248:107-23.

10. Hosseinpoor AR, Parker LA, Tursan d'Espaignet E, et al. Socioeconomic inequality in smoking in low-income and middleincome countries: results from the world health survey. PLoS One 2012;7:e42843.

11. Jha P, Peto R, Zatonski W, et al. Social inequalities in male mortality, and in male mortality from smoking: indirect estimation from national death rates in England and Wales, Poland, and North America. The Lancet 2006;368:367-70.

12. Huisman M, Kunst AE, Mackenbach JP. Educational inequalities in smoking among men and women aged 16 years and older in 11 European countries. Tob Control 2005;14:106-13.

13. Huisman M, Kunst AE, Bopp M, et al. Educational inequalities in cause-specific mortality in middle-aged and older men and women in eight Western European populations. The Lancet 2005;365:493-500.

14. Huisman M, Kunst AE, Mackenbach JP. Inequalities in the prevalence of smoking in the European Union: comparing education and income. Prev Med 2005;40:756-64. 
15. Peretti-Watel P, Constance J, Seror V, et al. Cigarettes and social differentiation in France: is tobacco use increasingly concentrated among the poor? Addiction 2009;104:1718-28.

16. Sreeramareddy CT, Pradhan PMS, Mir IA, et al. Smoking and smokeless tobacco use in nine South and Southeast Asian countries: prevalence estimates and social determinants from demographic and health surveys. Popul Health Metr 2014;12:22.

17. Sreeramareddy CT, Pradhan PM, Sin S. Prevalence, distribution, and social determinants of tobacco use in 30 sub-Saharan African countries. BMC Med 2014;12:243.

18. Sreeramareddy CT, Harper S, Ernstsen L. Educational and wealth inequalities in tobacco use among men and women in 54 low-income and middle-income countries. Tob Control 2018;27:26-34.

19. Bacigalupe A, Esnaola S, Martín U, et al. Two decades of inequalities in smoking prevalence, initiation and cessation in a southern European region: 1986-2007. Eur J Public Health 2013;23:552-8.

20. Giskes K, Kunst AE, Ariza C, et al. Applying an equity lens to tobacco-control policies and their uptake in six Western-European countries. J Public Health Policy 2007;28:261-80.

21. Garrett BE, Dube SR, Babb S, et al. Addressing the social determinants of health to reduce tobacco-related disparities. Nicotine Tob Res 2015;17:892-7.

22. Hill S, Amos A, Clifford D, et al. Impact of tobacco control interventions on socioeconomic inequalities in smoking: review of the evidence. Tob Control 2014;23:e89-97.

23. Hosseinpoor AR, Bergen N, Schlotheuber A, et al. National health inequality monitoring: current challenges and opportunities. Glob Health Action 2018;11:1392216

24. Giskes K, Kunst AE, Benach J, et al. Trends in smoking behaviour between 1985 and 2000 in nine European countries by education. $J$ Epidemiol Community Health 2005;59:395-401.

25. Hoebel J, Kuntz B, Kroll LE, et al. Trends in absolute and relative educational inequalities in adult smoking since the early 2000s: the case of Germany. Nicotine Tob Res 2018;20:295-302.

26. Corsi DJ, Neuman M, Finlay JE, et al. Demographic and health surveys: a profile. Int J Epidemiol 2012;41:1602-13.

27. Filmer D, Pritchett L. Estimating Wealth Effects without Expenditure Data--or Tears: An Application to Educational Enrollments in States of India. Policy Research Working Papers No. 1994; 1998.

28. Ahmad OB, Boschi-Pinto C, Lopez AD, et al. Age standardization of rates: a new WHO standard. Geneva: World Health Organization, 2001: 9. 10

29. Kunst AE, Mackenbach JP. Measuring socioeconomic inequalities in health. In: Measuring socioeconomic inequalities in health. World Health Organization, 1990.

30. Connor Gorber S, Schofield-Hurwitz S, Hardt J, et al. The accuracy of self-reported smoking: a systematic review of the relationship between self-reported and cotinine-assessed smoking status. Nicotine Tob Res 2009;11:12-24.

31. Jung-Choi K-H, Khang $\mathrm{Y}-\mathrm{H}$, Cho $\mathrm{H}-\mathrm{J}$. Hidden female smokers in Asia: a comparison of self-reported with cotinine-verified smoking prevalence rates in representative national data from an Asian population. Tob Control 2012;21:536-42.

32. Vartiainen E, Seppälä T, Lillsunde $P$, et al. Validation of self reported smoking by serum cotinine measurement in a community-based study. J Epidemiol Community Health 2002;56:167-70.

33. Bhan N, Karan A, Srivastava S, et al. Have socioeconomic inequalities in tobacco use in India increased over time? trends from the national sample surveys (2000-2012). Nicotine Tob Res 2016;18:1711-8.

34. Pampel FC. The persistence of educational disparities in smoking. Soc Probl 2009;56:526-42.

35. Lahelma E, Pietiläinen $\mathrm{O}$, Ferrie J, et al. Changes over time in absolute and relative socioeconomic differences in smoking: a comparison of cohort studies from Britain, Finland, and Japan. Nicotine Tob Res 2016;18:1697-704.

36. Ernstsen L, Strand BH, Nilsen SM, et al. Trends in absolute and relative educational inequalities in four modifiable ischaemic heart disease risk factors: repeated cross-sectional surveys from the Nord-Trøndelag health study (HUNT) 1984-2008. BMC Public Health 2012;12:266.

37. Harper S, Lynch J. Trends in socioeconomic inequalities in adult health behaviors among U.S. states, 1990-2004. Public Health Rep 2007;122:177-89.

38. Scholes S, Bajekal M, Love H, et al. Persistent socioeconomic inequalities in cardiovascular risk factors in England over 1994-2008: a time-trend analysis of repeated cross-sectional data. BMC Public Health 2012;12:129.

39. Ding D, Do A, Schmidt $\mathrm{H}-\mathrm{M}$, et al. A widening gap? changes in multiple lifestyle risk behaviours by socioeconomic status in New South Wales, Australia, 2002-2012. PLoS One 2015;10:e0135338.

40. Tabuchi T, Iso H, Brunner E. Tobacco control measures to reduce socioeconomic inequality in smoking: the necessity, time-course perspective, and future implications. J Epidemiol 2018;28:170-5.

41. Ministry of Health and Population. Tobacco Control and Regulation Act 2011. MOHP, 2011. Ministry of Health and Population Kathmandu, Nepal; 2011.

42. Smith $P$, Frank J, Mustard $\mathrm{C}$. Trends in educational inequalities in smoking and physical activity in Canada: 1974-2005. J Epidemiol Community Health 2009;63:317-23.

43. Cummings KM. Community-wide interventions for tobacco control. Nicotine Tob Res 1999;1:S113-6. 